\title{
Systematics of Nepalese Termitomyces
}

\author{
Hari Prasad Aryal $^{1^{*}}$ and Usha Budathoki ${ }^{2}$ \\ ${ }^{I}$ Bhairahawa Multiple Campus, Siddarthanagar,Nepal \\ ${ }^{2}$ Central Department of Botany, Tribhuvan University, Kathmandu, Nepal \\ "E-mail: hahariprasadaryal06@gmail.com
}

Received: 2015.08.15, Accepted: 2015.10.13

\begin{abstract}
The genus Termitomyces is obligate symbiont fungus with the termite, which grows on termatoria. This paper highlights new records of Termitomyces aurantiacus (R. Heim) R. Heim, T. badius Otieno, T. le-testui (Pat.) R. Heim, T. microcarpus $f$. santalensis Heim and T. schimperi (Pat.) R. Heim reported for the first time from Nepal. The collection area lies 26 $44^{\circ} 08^{\prime \prime}-29^{\circ} 06^{\prime} 32^{\prime \prime} \mathrm{N}$ latitude and $80^{\circ} 18^{\prime} 02^{\prime \prime}-88^{\circ} 08^{\prime} 27^{\prime \prime} \mathrm{E}$ longitude within an altitudinal range of 60-3000 msl. The collection during 2010-2012 from reserve forest and the specimens have been deposited in the Natural History Museum (NHM), Tribhuvan University, Kathmandu, Nepal.
\end{abstract}

Kew words: Basidiomycetes, Phytogeography, Taxonomy, Termitophilous fungi.

\section{Introduction}

This genus Termitomyces belonging to the family Lyophyllaceae, is characterized by typical agaricoid fruiting body, carpophores pluteoid, usually fleshy, with large often sharply, differentiated umbo, stipe central, spore print creamy to pink, lamellae free to adnexed but with decurrent tooth stipe with pseudorrhiza and with simple veil, hyphae, inamyloids, with a hilum of the open pore type, ellipsoid, smooth, basidia normal, cystidia present, tramal hyphae inamyloids, with or without clamp connection, trame system monomitic, having lamellate hymenophore. The genus is represented by giants among the gilled mushrooms like $T$. titanicus ( $\geq 1 \mathrm{~m}$ cap diam.) as well as by small mushrooms, like T. microcarpus $(\leq 2$ cm cap diam.) (Tibuhwa et al., 2010).

This medicinally important tropical genus has a symbiotic life together with termites (Aryal and Budhathoki, 2014). Its fructification period is strongly seasonal. It comprises fungi that live in an obligate symbiosis with termites of the subfamily Macrotermitinae. This investigation is based on the detailed study on the macro and micro morphological characters of the collected samples from the field.

\section{Materials and methods}

Exhaustive surveys of various localities of different place of country were conducted for the collection of samples (Fig. 1). The number of sites were supervised 81 forests, among them 45 forests were randomly chosen by Randomized Block design (RBD) method (Elliott, 1971). The total of 3 spots was sampled from each topography of Eastern, Central and western region of Nepal. Altogether a total of 27 spots were sampled from narrow down by 27 forest (including agricultural and barren land) occupies area (where each spot represents the 10 quadrants). The actual information of 
these areas was noted from the interaction with 300 members of the individuals of ethnic groups. Herein, participatory rural appraisal (PRA) technique (Frendenberger, 2011) was adopted with the local people to get information on nutritional as well as medicinal aspects. The collection was entirely based on their sexual reproductive structures (Atri et al., 2005a; 2010). The habit and habitat including ecological parameters were recorded using accessory equipments.

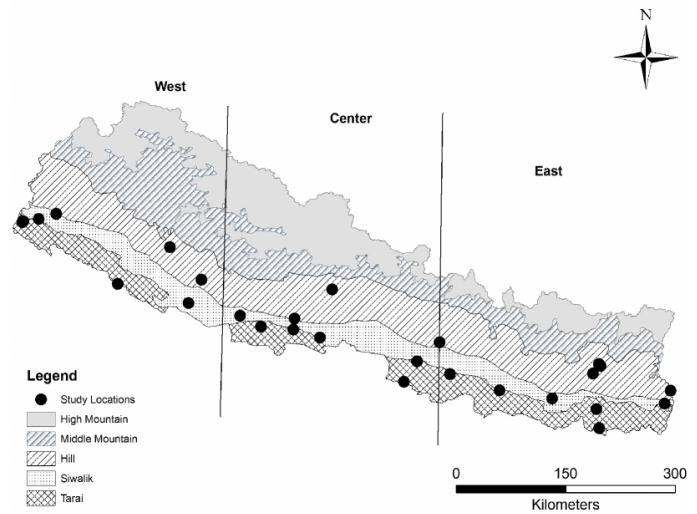

Figure 1. Sample collection sites

Macroscopic characters and photomicrographs of the internal features of systematic importance were noted. The cyanophility was observed by placing the parts of materials in cotton blue and mounting in $0.01 \%$ lactophenol (Kirk et al., 2008 ) and amyloidity of spores was observed by using Melzer's reagent (Melzer,1924). Xanthochoric reaction was also tested using $5 \% \mathrm{KOH}$. These specimens were studies under an Olympus microscope (Model CX 22, Japan). The measurements were taken with the help of ocular micrometer. The classification was adopted given by of (Kuo, 2006).

The voucher specimens were identified using publication of Heim (1977), Bels and Pateregetvit (1982), Singer (1986), Atri et al., (2005b), Harkonen et al. (2003) and on line data base such as: Biodiversity Library.org, Index Fungorum, Mycobank.org and Tropicos.org.

\section{Results}

1. Termitomyces aurantiacus (R. Heim) R. Heim, Termites et Champignons (Paris), 56: 205(1977) (Plate 1).

\section{Local name: Chotki Vend (Awadhi)}

Taxonomic position: Division: Basidiomycota, class: Basidiomycetes, subclass: Agaricomycetidae, order: Agaricales, family: Tricholomataceae.

Identifying characters: The most distinguishing characters of this species are medium size cap, (10-15 cm in diameter), brown to grey, smooth, glabrous. Perforatorium small, olivaceous broadly conical, a continuation of cap, demarcated and prominent, partly blackish, dark coloured projection at the center of the cap, not so long spiniform papilla, demarcated as umbonate, dark grey in colour. Cap umbonate, without velar remnant, margin incurved, stipe with pseudorrhiza pale, not entirely blackish, originating from termite nest; no sclerotium, no annulus.

\section{Description:}

Sporophores: Usually growing solitary in termite hills, characterized by its obligate symbiont with termites; usually centrally stipitate white but olivaceous near the umbonal region.

Pileus: Size 10-15 cm, (Medium size) brown to grey towards margin, olivaceous at the apex, umbonate, surface smooth, incurved margin. Lamellae: Free, dense, 
crowded, white to pale grey. Stipe: Solid, swollen at base, size $7-9 \times 2.0-2.5 \mathrm{~cm}$, silvery

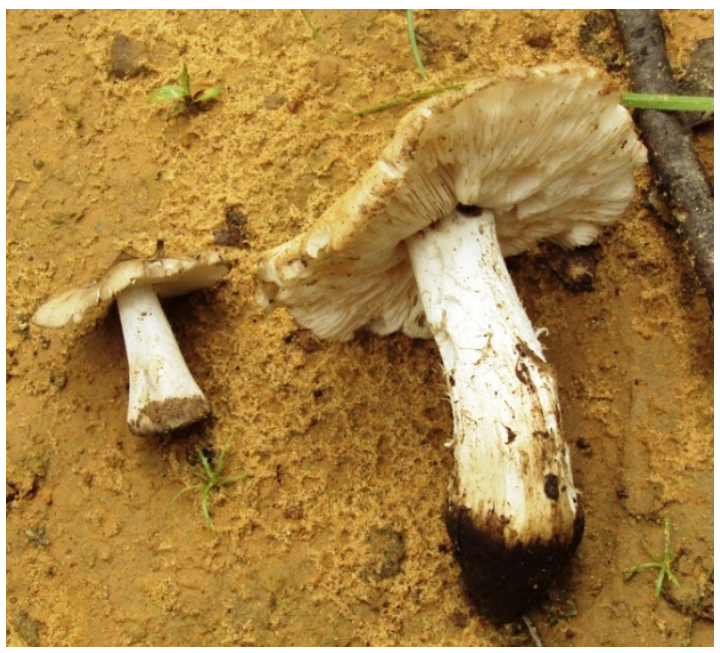

Basidiocarps

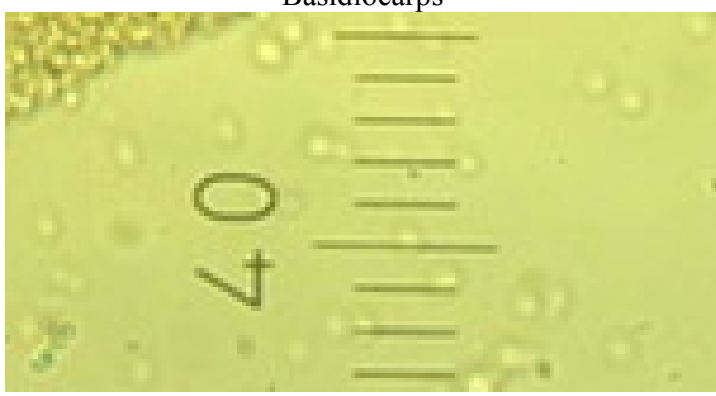

Spores

Plate 1. Termitomyces aurantiacus (R. Heim) R. Heim

absent. Pseudorrhiza: Size $5 \times 0.5 \mathrm{~cm}$ long, solid, dark brown in colour, surface cartilaginous, solid and widening at certain depth, then narrowing down to the point of attachment to the termite nest, its length determined by the depth of the termite comb. Flesh: Soft, thin walled, white, inflated, clamp connection absent, nonamyloid. Spore print: Pink. Basidia: 21.5-23.5 ×4.9-6.9 $\mu \mathrm{m}$. Basidiospores: 5.57.5×3.5-5.5 $\mu \mathrm{m}$, ellipsoid. Cystidia: 24$26 \times 10.5-12.5 \mu \mathrm{m}$ Hymenophoral trama: regular. white, surface smooth, fibrous, annulus
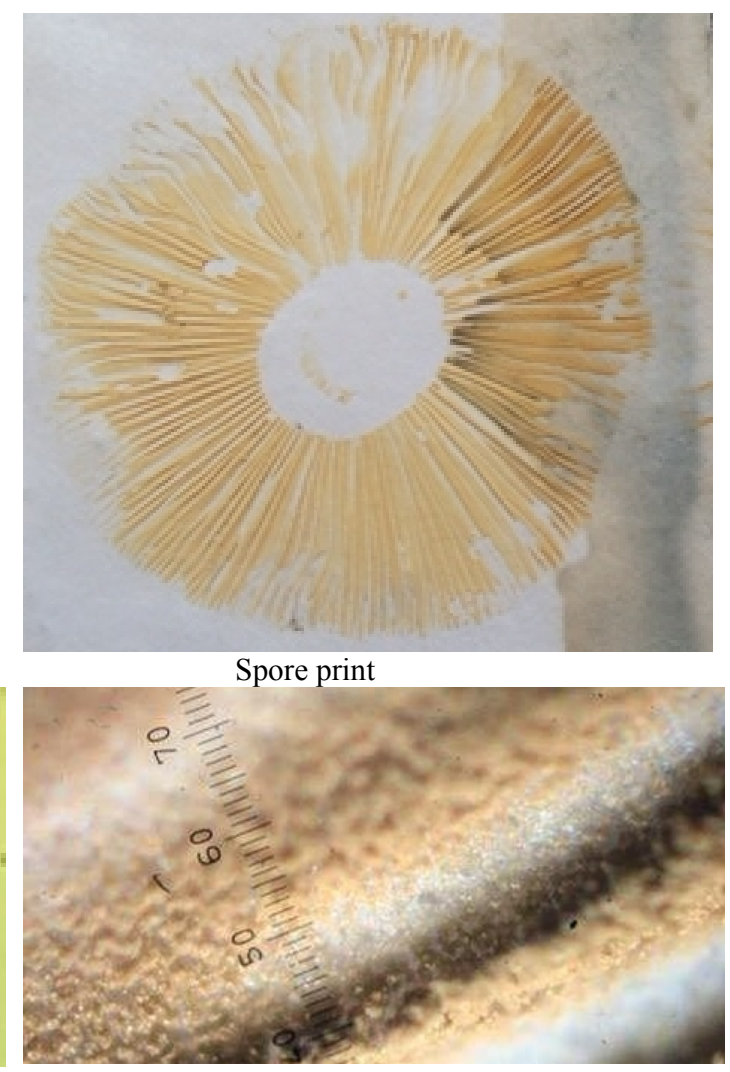

Lamellae

Habitat: On termite nests in tropical forest. Fruiting season: July-September.

Specimen examined: Growing on surface land on soil, common in Sal (Shorea robusta) dominant forest, Rupandehi (Kumhargaddi), Alt.: 195m, long. $83.26236^{\circ} \mathrm{E}$, lat. $27.29245^{\circ} \mathrm{N}$, Aspect: $140^{\circ}$ S/E; Slop: $20^{\circ} \mathrm{S} / \mathrm{W}$; Temp.: $21.9-32.3^{\circ} \mathrm{C}$; Humidity: 69-87 \%; Soil pH: 6; Time: 9:06 am; Date: 04.08.2011. Accession No. NHM TU 2-2-1682. Report for new to Nepal. 
Distribution: Equatorial, southern Africa, Madagascar, S.E. Asia including Nepal.

2. Termitomyces badius Otieno, Sydowia 22(1-4): 161 (1969) (Plate 2).

Local name: Kanayo (Kumhal)

Taxonomic position: Division: Basidiomycota class: Basidiomycetes subclass: Agaricomycetidae order: Agaricales family: Tricholomataceae.

Identifying characters: The most distinguishing characters of this species are the silky, smooth, glabrous, white stipe with dark brown to blackish pseudorrhiza originating from termite nest; no Sclerotium. Cap medium in size (up to 10 $\mathrm{cm}$ in diameter). Colour ochraceous-grey, without velar remnant, umbonate. Perforatorium are umbo, olive, margin radially straight, incurved. Pseudorrhiza is small (up to $5 \mathrm{~cm}$ ), absence of clamp connection. Sporophores are, growing on sandy soil in groups or on the shaded ground in association with termite's nests.

\section{Description:}

Usually growing solitary in termite hills, characterized by its obligate symbiont with termites; usually centrally stipitate white but olivaceous near the umbonal region.

Sporophores: Spread of this fungus is quite striking; they are abundantly found solitary in the humus rich grass land or termite disused nests, characterized by its obligate symbiont with termites; usually centrally stipitate white but olivaceous near the umbonal region.

Pileus: Size 10-14 cm (Medium size) in diameter; umbonate in shape, surface smooth, glabrous, pale grey in colour, radially straight, incurved margin, dark brown; olive in the centre, papillate, umbo. Lamellae: free dense, grey in colour. Stipe: Size $5.2 \times 0.75 \mathrm{~cm}$ long, more or less straight, solid, white, surface smooth, glabrous, absent of annulus, a part of it is inside the soil, nearly $3.2 \mathrm{~cm}$. Pseudorrhizea: Size $5 \times 1 \mathrm{~cm}$ long, solid, brown in colour, cylindrical, glabrous, smooth, and widening at certain depth, then narrowing down to the point of attachment to the termite nest, its length determined by the depth of the termite comb. Flesh: whitish, soft, inflated, clamp connection absent, thin walled, non-amyloid. Spore print: Pinkish Basidia: 23-25×6-8 $\mu \mathrm{m}$, clavate, Basidiospores: 4 in number, smooth, hyaline, 5.5-7.5 $\times 2.5-4.5 \mu \mathrm{m}$, ellipsoidal, Cystidia: $18-20 \times 9.5-11.5 \mu \mathrm{m}$. Hymenophoral trama: regular

Habitat: On termite nests in tropical forest. Fruiting season: July-September.

Specimen examined: Growing on termite disused nests, common. Nawalparasi (Arunkhola), Alt.: $202 \mathrm{~m}$, long. $84.05827^{\circ} \mathrm{E}$; lat. $27.62584^{\circ} \mathrm{N}$; Aspect: $50^{\circ} \mathrm{N} / \mathrm{E}$; Slope: $12^{\circ} \mathrm{S} / \mathrm{W}$; Temp.: $21.9-30.1^{\circ} \mathrm{C}$; Humidity: 64-87\%; Soil pH: 5.62; Time: 2:00 pm., Date: 24.07.2011. Accession No. NHM TU 2-2-1683. Report for new to Nepal.

Distribution: Equatorial, southern Africa, Madagascar, South East Asia including Nepal.

3. Termitomycs le-testui (Pat.) R. Heim, Arch. Mus. Hist. Nat. Paris, ser. 6, 18: 109 (1942). (Plate 3)

Local name: Dudhamunte 
Hari Prasad Aryal and Usha Budathoki / Our Nature (2015), 13(1): 31-44.
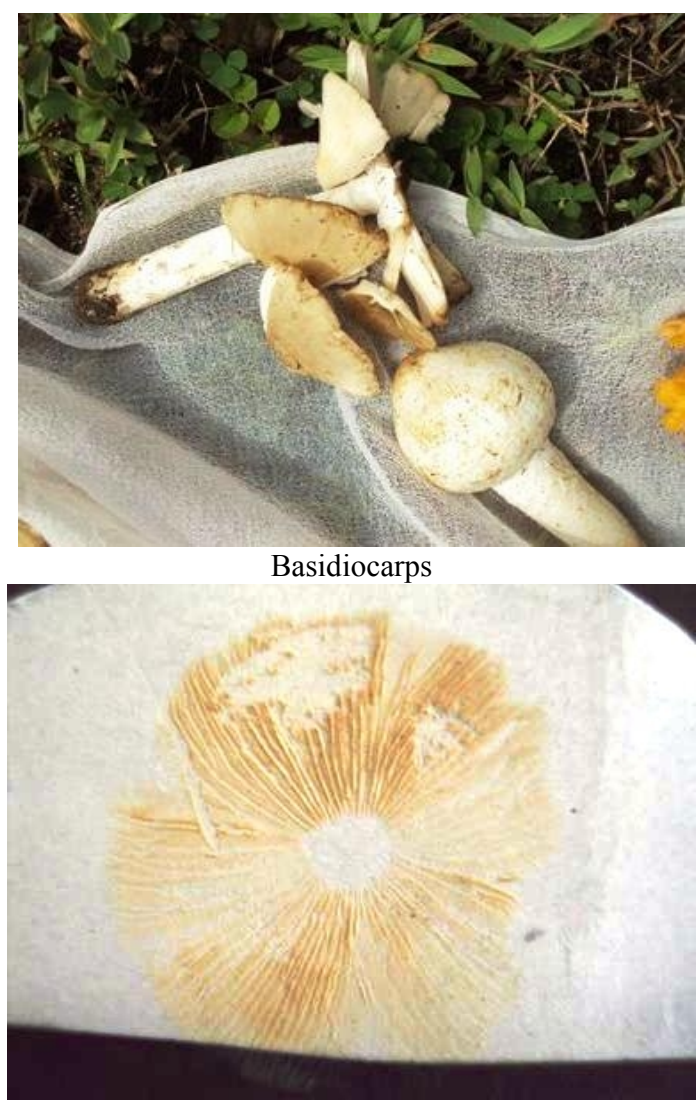

Spore print

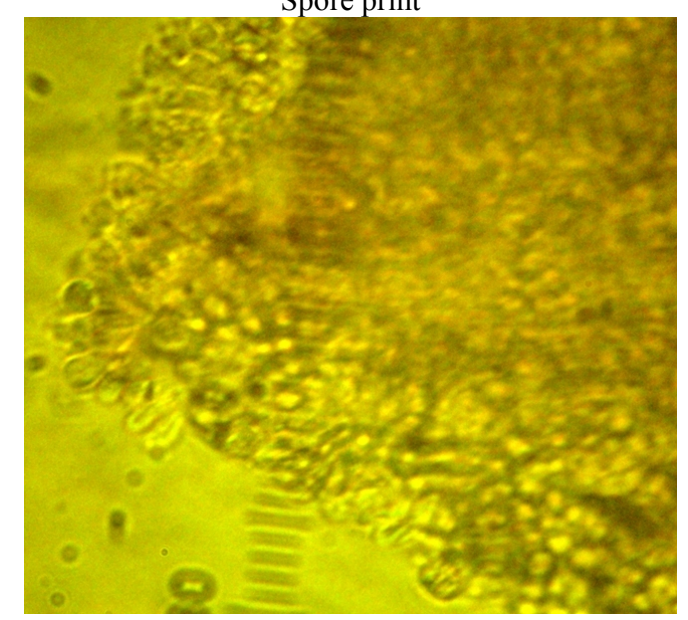

Basidia with basidiospores
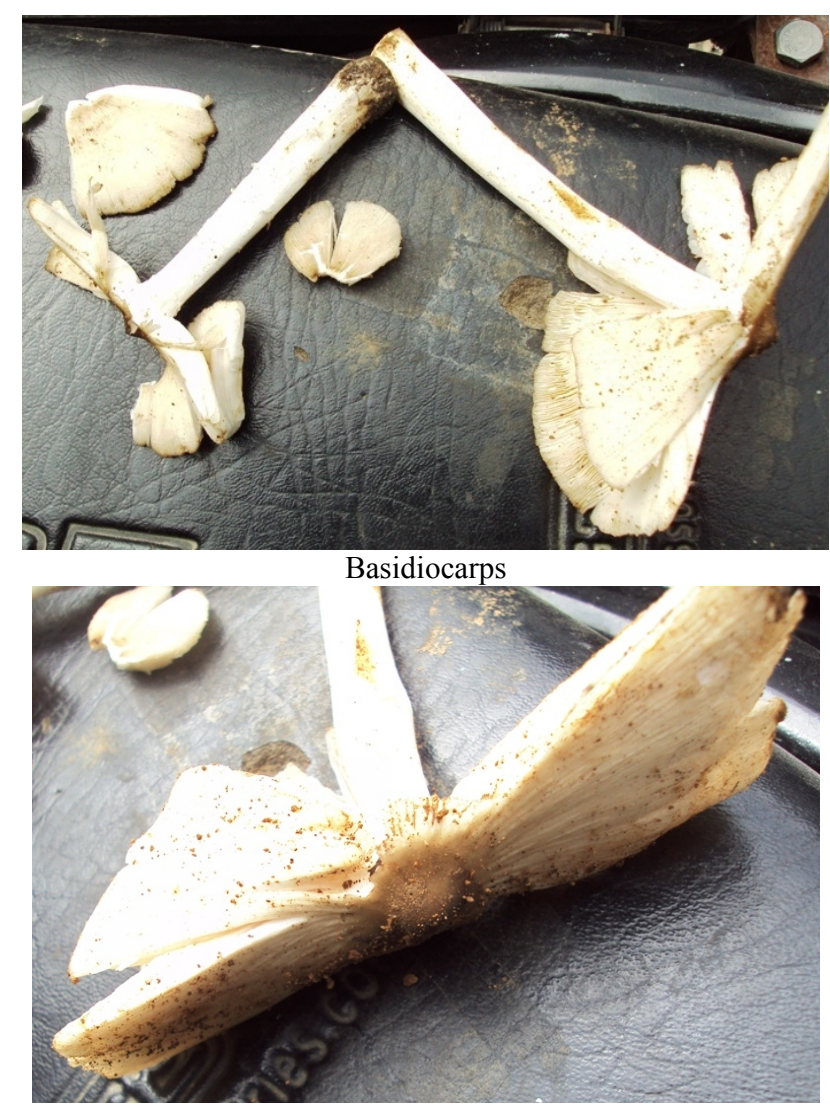

Basidiocarps

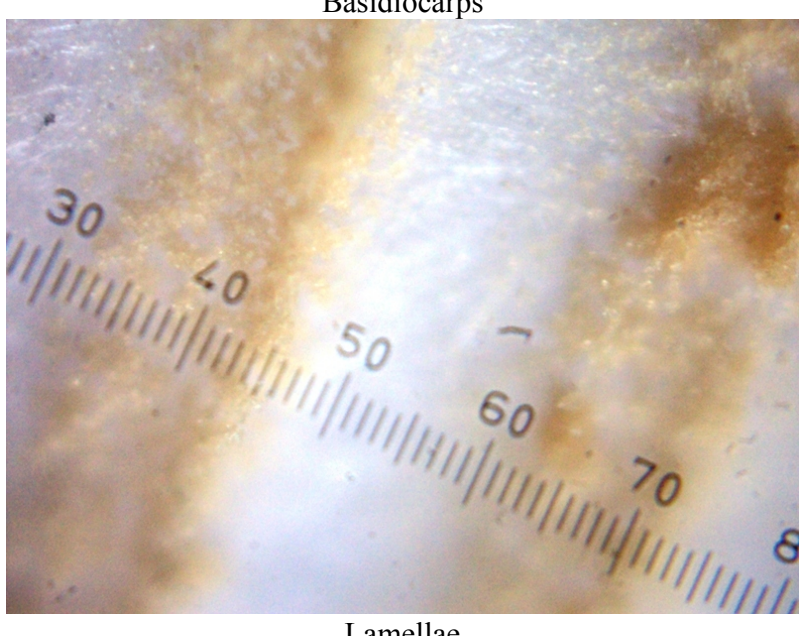

Lamellae

Plate 2. Termitomyces badius Otieno 
Taxonomic position: Division: Basidiomycota class: Basidiomycetes sub-class: Agaricomycetidae order: Agaricales family: Tricholomataceae.

Identifying characters: The most distinguishing characters of this species are, cap brownish or black brown, larger, 21.0$22.5 \mathrm{~cm}$ in diameter, tomentose; perforatorium prominent, cylindric, smooth, dark brown, demarcated and prominent, either subnammillate, mammiform or cylindric, long, continuous projection at the center of the cap as a 'teat of mammals' like structure of papilla, stipe with long pseudorrhizea originating from termite nest; no sclerotium, annulus persistent. Sporophores are found in groups, growing on the sandy soil or on the shaded ground in association with termite's nests.

\section{Description}

Sporophores: Growing on termite nests in early to during monsoon period. The fruitbodies from inside the tunnels and bore through the very hard layer of insert matter, forming their way through it with a special umbo, sometimes quite pointed, called a "driller." A 'teat' likes structure.

Pileus: size $21.0-22.5 \mathrm{~cm}$, (large), cream to light brown, fleshy, campanulate then convex, eventually fairly expanded, with a conspicuous cylindrical umbo of perforatorium, which is dark brown from the small brown scales about disc. Cutical, dry and whitish, fairly pale pinkish-gray, squamulose and cracked except toward margin, which is usually appendiculate. Lamellae: white, almost free, crowded, unequal. Stipe: size $12.0-18.0 \times 2.0-3.0 \mathrm{~cm}$ or more, solid, fusiform, deeply rooting, cream to whitish, pubescent beneath membranous ring, which is large, double, variable but complete and persistent, pendant or sheath like. Pseudorrhizea: $18 \times 1.5 \mathrm{~cm}$ long, dark in colour, hollow, cylindrical and widening at certain depth, than narrowing down to the point of attachment to the termite nest, its length determined by the depth of the termite comb. Flesh: whitish, soft, thin walled, interwoven, nonamyloid, hyaline hyphae, clamp connection absent. Spore print: Pinkish. Basidia: 23.1-25.1×6.3-8.3 $\mu \mathrm{m}$, tetra sterigmata bearing tetra basidiospores. Basidiospores: 6.25$8.25 \times 2.5-4.5 \mu \mathrm{m}$, oblong. Cystidia: 35 $37 \times 14-16 \mu \mathrm{m}$.

Habitat: On termite nests in tropical forest. Fruiting season: July-September.

Specimen examined: Growing on termite nest, common in Sal forest, Nawalparasi (Basabasahi), 130m, long. $83.65415^{\circ} \mathrm{E}$, lat. $27.62274^{\circ} \mathrm{N}$, Aspect: $198^{\circ} \mathrm{S} / \mathrm{W}$; Slope: $10^{\circ}$ S/W; Temp.: 21.9-29. ${ }^{\circ} \mathrm{C}$; Humidity: 7987\%; Time: 9:10 am. Date: 18.09.2011. Accession No. NHM TU 2-2-1670. Report for new to Nepal.

Distribution: Equatorial, southern Africa, Madagascar, South East Asia including Nepal.

4. Termitomyces microcarpus (Berk. \& Br.) Heim forma Santalensis Heim, Mem. Acad. Sci. Inst. France 64: 73 (1941) (Plate 4)

Local name: Jhari (Magar), Rai (Tharu)

Identifying characters: This fungus grows abundantly in open grass land. It is marked by presence of pseudorrhiza. Pileus up to 4 $\mathrm{cm}$ diameter, presence of conic papilla. 
Hari Prasad Aryal and Usha Budathoki / Our Nature (2015), 13(1): 31-44.

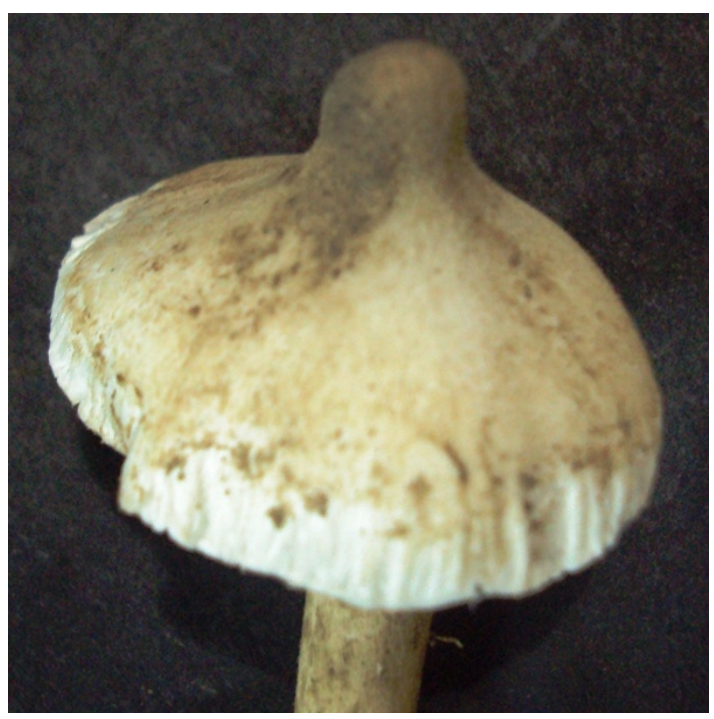

Basidiocarp

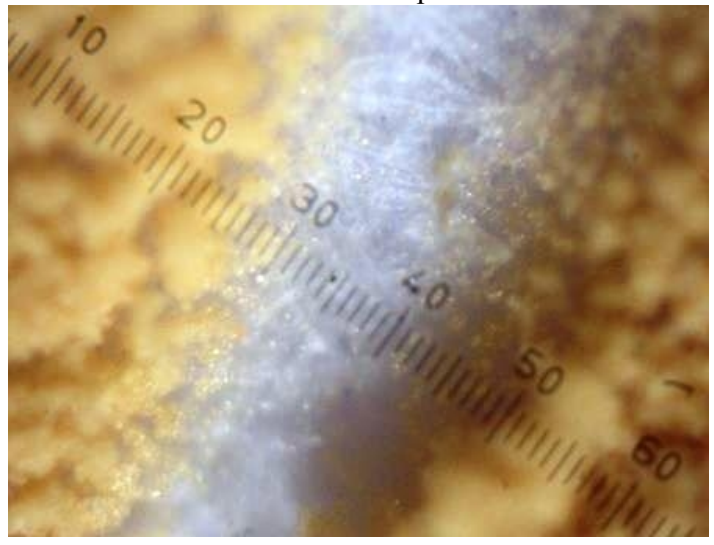

Lamellae

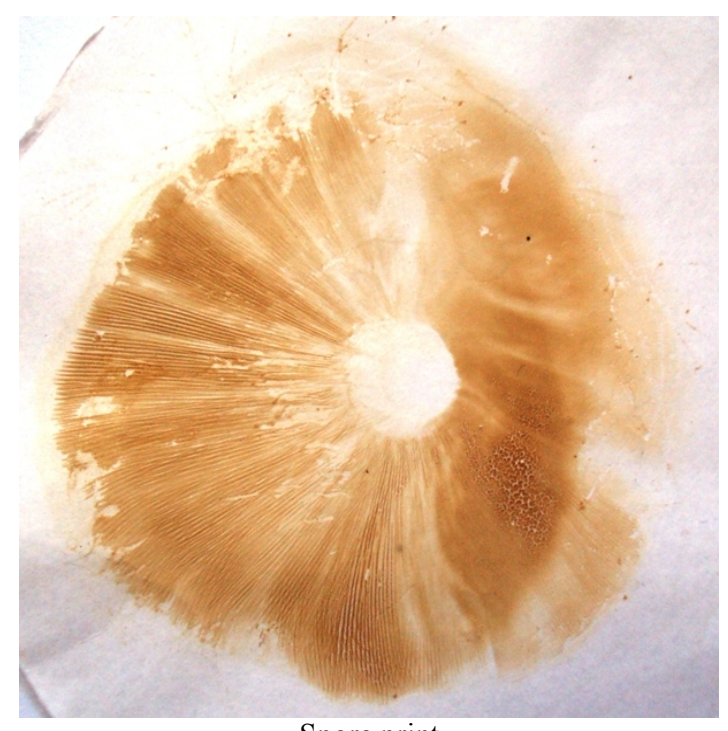

Spore print

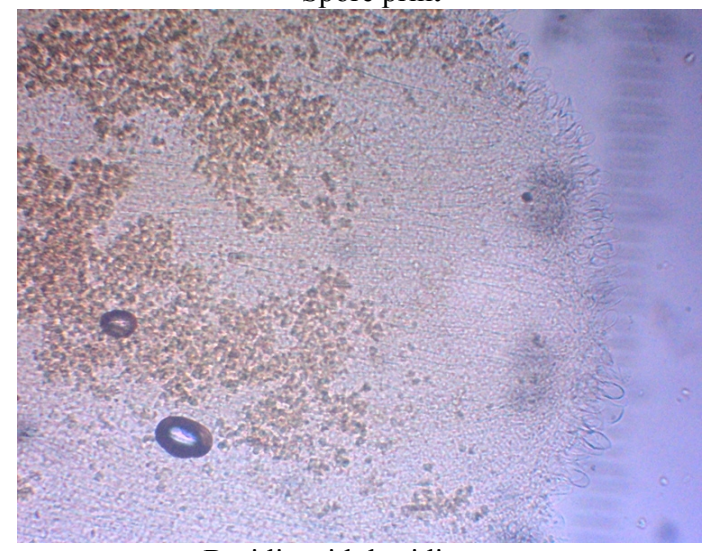

Basidia with basidiospores

Plate 3. Termitomyces le-testui (Pat.) R. Heim

\section{Description}

Sporophores: Usually growing solitary in termite hills, characterized by its obligate symbiont with termites; usually centrally stipitate white but olivaceous near the umbonal region.

Pileus: 1-4 cm, whitish to grey in colour, papillate, conic, becoming olivaceous to brown at the papilla non-viscid, smooth, margin thin, incurved, entire, or incised. Lamellae: sinuate, concolourous, arcuate, crowded, with lamellulae of three unequal length; edge entire, smooth, concolourous. Stipe: $3-8 \times 0.4-0.6 \mathrm{~cm}$, central, straight, cylindrical, grey in colour, surface smooth, annulus absent. Pseudorrhiza: attenuated at the base to form a long, solid, greyishbrown in colour, $5 \times 0.3 \mathrm{~cm}$, hollow, slender, cylindrical, surface glabrous, smooth, and 
Hari Prasad Aryal and Usha Budathoki / Our Nature (2015), 13(1): 31-44.

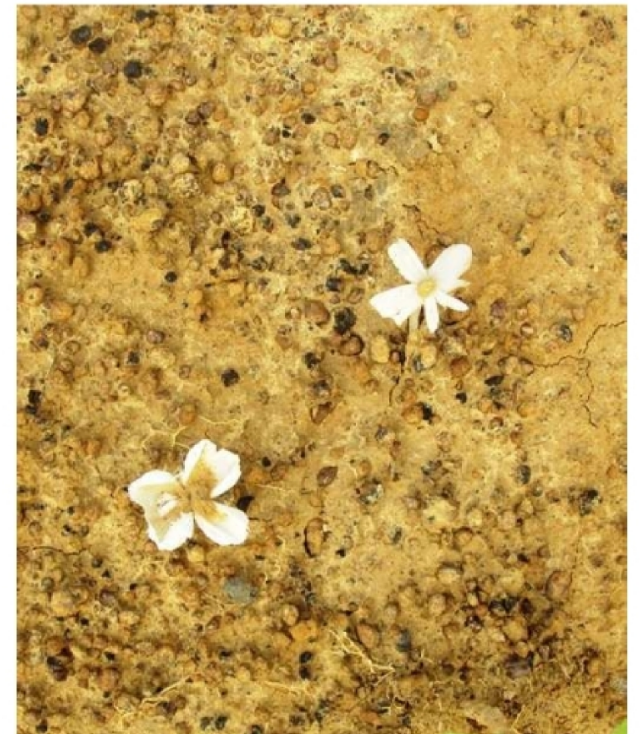

Basidiocarps

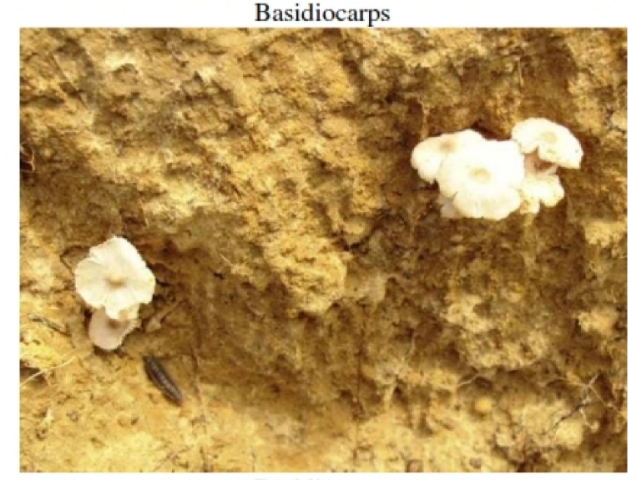

Basidiocarps

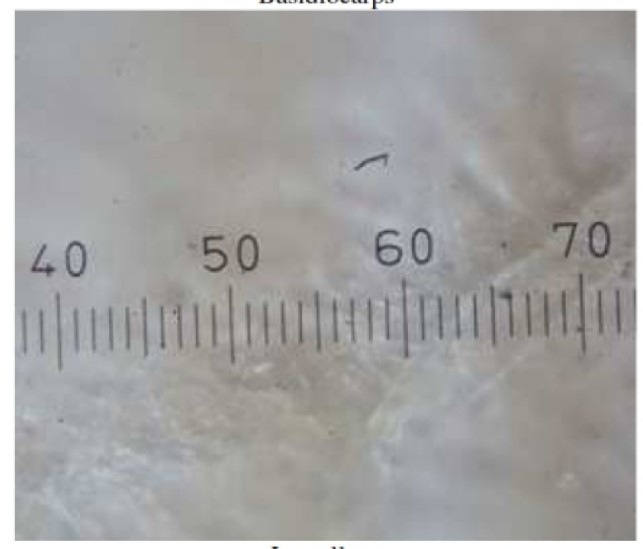

Lamellae

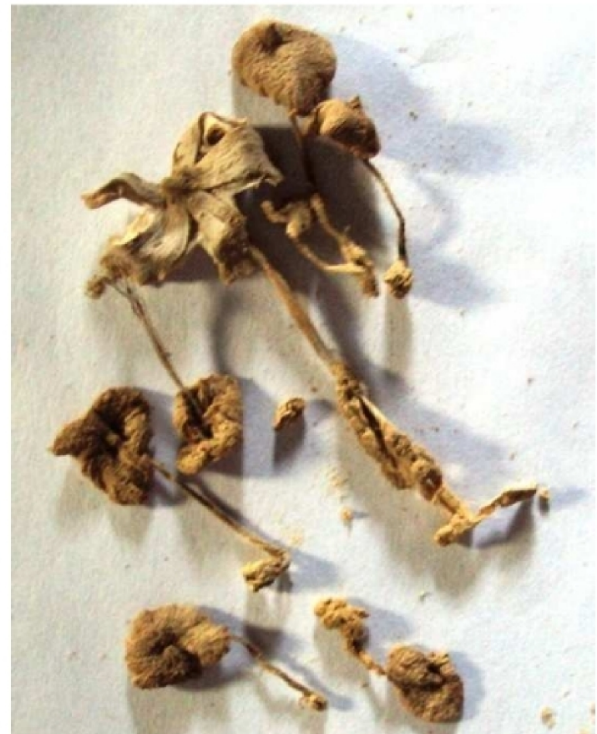

Dried basidiocarps

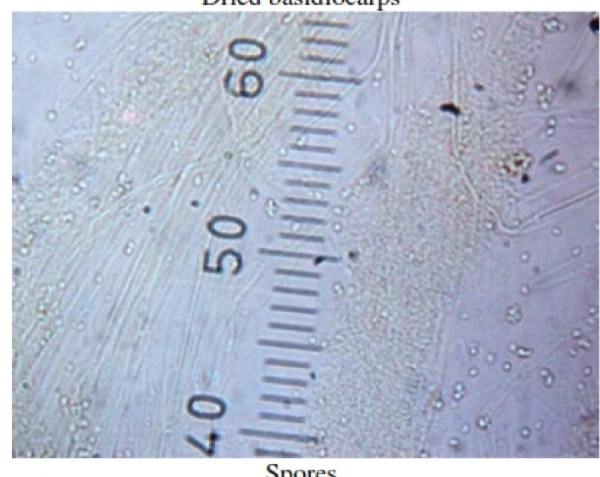

Spores

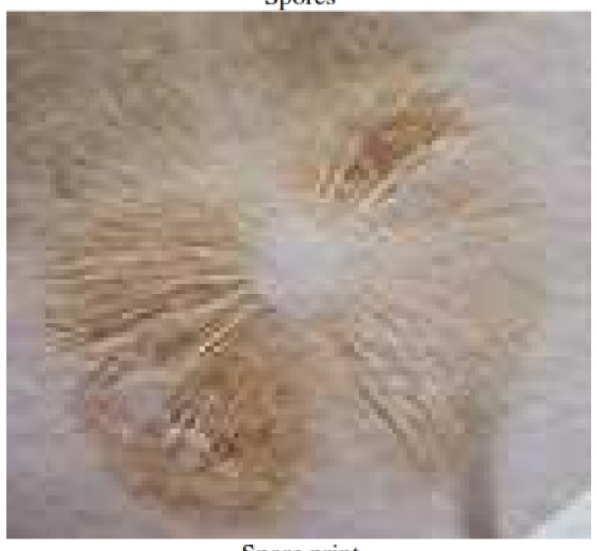

Spore print

Plate 4. Termitomyces microcarpus (Berk. \& Br.) Heim forma Santalensis Heim 
Hari Prasad Aryal and Usha Budathoki / Our Nature (2015), 13(1): 31-44.

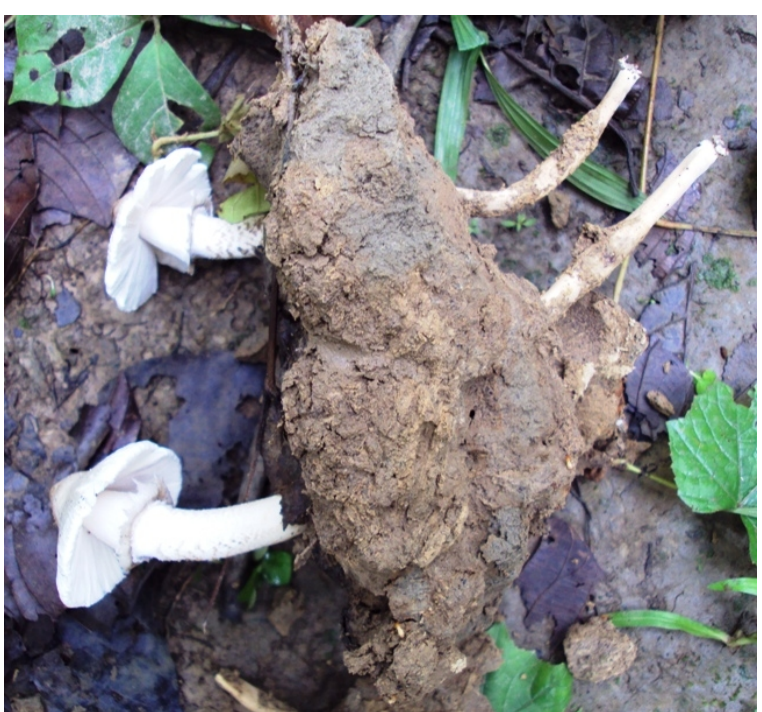

Basidiocarps

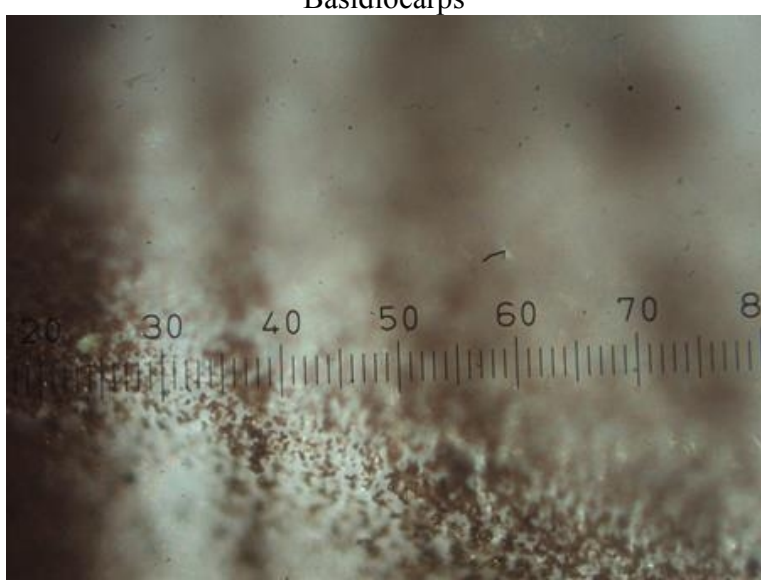

Lamellae

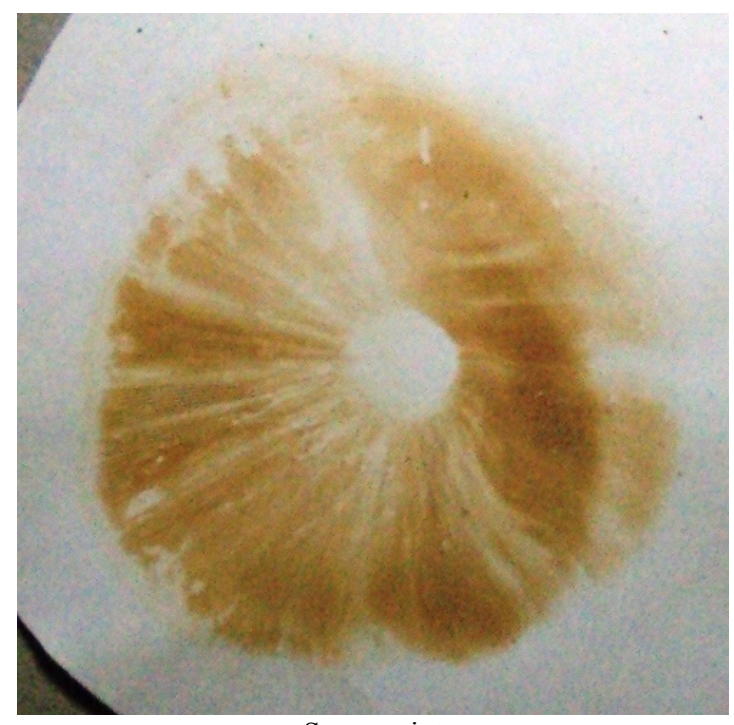

Spore print

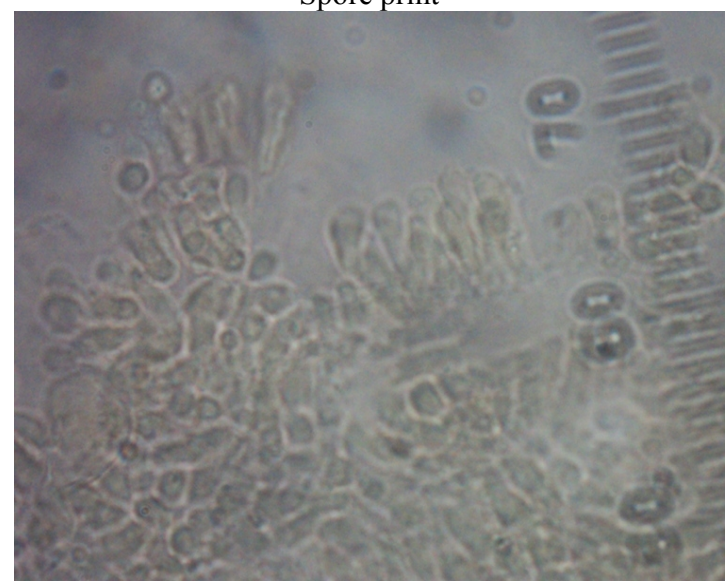

Basidia with spores

Plate 5. Termitomyces schimperi (Pat.) R. Heim

widening at certain depth, then narrowing down to the point of attachment to the termite nest, its length determined by the depth of the termite comb. Flesh: Spongy, whitish, consisting of interwoven hyphae, which are nonnamyloid, thin-walled, inflated hyphae, with clamp-connection. Spore-Print: Brown. Basidia: 15-20×5-7 $\mu \mathrm{m}$, clavate, bears 4-sterigmata. Basidiospores: $5-7 \times 3-5 \mu \mathrm{m}$, ellipsoidal.
Cystidia: 23-25×11-13 $\mu \mathrm{m}$. Hymenophoral trama: sub regular, hyaline, inamyloid, consisting of thin walled hyphae.

Habitat: On termite nests in tropical forest. Fruiting season: July-September.

Specimen examined: Growing on open surface on pine forest, Salyan (Aringalependi-Dhanwag VDC-1), 1110m, long. $82.37703^{\circ} \mathrm{E}$, lat. $28.25742^{\circ} \mathrm{N}$; Aspect: 
124 ${ }^{\circ} \mathrm{S} / \mathrm{E} ;$ Slop: $40^{\circ} \mathrm{S} / \mathrm{W}^{;}$Temp.: 21.9$28.5^{\circ} \mathrm{C}$; Humidity: $76-87 \%$; Soil pH: 5.62; Time: 13:35 pm. Date: 24.08.2011. Accession No. NHM TU 2-2-1679. Report for new to Nepal.

Distribution: Equatorial, southern Africa, Madagascar, South East Asia including Nepal.

5. Termitomyces schimperi (Pat.) R. Heim, Arch. Mus. Hist. Nat. Paris, ser. 6, 18: 114 (1942). (Plate 5)

\section{Local name: Dhamire.}

Taxonomic position: Division: Basidiomycota class: Basidiomycetes subclass: Agaricomycetidae order: Agaricales family: Tricholomataceae.

Identifying characters: The most distinguishing characters of this species is larger cap (usually at least $4 \mathrm{~cm}$ diameter), white, with distinct velar remnants, and large squamules; perforatorium not so long spiniform, prominent, demarcated, broadly conical, a continuation of cap, dark coloured projection at the center of the cap. Stipe with long pseudorrhiza, originating from termite nest; no sclerotium. Sporophores are found in groups, growing on the sandy soil or on the shaded ground in association with termite's nests.

\section{Description}

Sporophores: Usually growing solitary in termite hills, characterized by its obligate symbiont with termites; usually centrally stipitate white but olivaceous near the umbonal region.

Pileus: 20.5-21.0 cm, (large size), cream white with concentric rings of brown scales, margin incurved. Perforatorium are conical to bullate umbo, in shape, dark grey in colour. Lamella: whitish, dense, crowded and free. Stipe: $15 \times 2.5 \mathrm{~cm}$, creamy-white in colour, solid, surface smooth, glabrous. Annulus covered by thick membranous of velar remains. Pseudorrhizea: $17 \times 1.6 \mathrm{~cm}$, dark-brown in colour, solid, cylindrical, slender, surface smooth and widening at certain depth, than narrowing down to the point of attachment to the termite nest, its length determined by the depth of the termite comb. Flesh: whitish, thin walled, filamentous, nonamyloid, hyaline, clamp connection absent. Spore print: pale cinnamon. Basidia: 26.5-28.5 $\times 7-9 \mu \mathrm{m}$, tetra sterigmata bearing tetra basidiospores. Basidiospores: $\quad 5.5-7.5 \times 3.5-5.5 \mu \mathrm{m}$, ellipsoid. Cystidia: $\quad 31.5-33.5 \times 13.5-15.5$ $\mu \mathrm{m}$.

Habitat: On termite nests in tropical forest. Fruiting season: July-September.

Specimen examined: Growing on termite's hive, common in Shorea robusta, 1016 m, Lumbini zone, Palpa district, Mashyam, V.D.C. W.N. 9. Longitude: $83.50969^{\circ} \mathrm{E}$, latitude: $27.76451^{\circ} \mathrm{N}$, Aspect: $270^{\circ} \mathrm{W}$, Slope: $50^{\circ} \mathrm{S} / \mathrm{W}$, Temp.: $21.9-26.8^{\circ} \mathrm{C}$, Humidity: 79-87\%, Soil pH: 6.2, Time: 9:43 am, Date of collection: 17. 08. 2011. Accession No. NHM TU 2-2-1673. Report for new to Nepal.

Distribution: Equatorial, southern Africa, Madagascar, South East Asia including Nepal.

\section{Discussion \\ Regarding macro-morphological characters of the cap size, shape, margin, surface and colour vary according to age and environmental conditions. This character is}


very useful for narrowing the identification of the taxon. This also help in narrowing the wide-range of comparisons in the field guide and more systematically important, for making identification work easier (Heim, 1977; Harkonen et al., 1995, 2003).

Cap as a morphological feature being environmentally influenced (Alexopoulos and Mims, 1993). Piearce (1987), reported on the effects of the architecture, depth, size and nutritional status of the parent comb and resistance of the soil to the cap. Kunugawa and Furukawa (1965) found out that temperature affects the development of fruit bodies since mushrooms have their minimal, optimal and maximal temperatures for their healthy growth while Webester (1970) noted the effect of light intensity on mushroom fruit body morphology, often with much elongated stipe and poor cap development depending on the light intensity. Thus it can be said that on the basis of cap size, it is very useful for comparisons between the taxa for identification. A distinct umbo (or papilla) is one of the important diagnostic features of Termitomyces.

Colour of cap, perforatorium, gills, stipe, pseudorrhizea and flesh also help for identification of the taxon during present study. Colour is also a useful for confining the species of the genus (Heim, 1977). Colour of basidioma cap, stipe and lamellar are the most useful macro morphological characters but difficulty is that pigments responsible for these, are unknown in many groups of agarics including Termitomyces (Singer, 1986). So that it is necessary for more study to determine pigments responsible for particular type of colour in order to make distinguishing the characters. However variation of colour was found in this genus from whitish to greyish, greyish to brown and Tawny-brown to pale cream.

A distinct umbo (or papilla) is one of the important diagnostic features of Termitomyces. Shape of the perforatorium implies that some species are close to one another. For example T. badius have an umbo; similarly $T$. microcarpous $f$. santalensis have small spiniform papilla, whereas they differ to one another due to varied form of perforatorium for example $T$. le-testui, due to the presence of spiniform, cylindrical umbo "teat" perforatorium.

Ornamentation of gills also helps for narrowing the taxon during identification but it is less significant for reaching the species level, because all the Termitomyces having free, crowded and dense lamellae.

Shape, size and surface of the stipe also help for narrowing the species but it is less significant for determining the species level, because usually all the Termitomyces having solid, cylindrical, and long.

Presence of an annulus in termitomycetes also serves as an important character. It varies from completely absent to microscopic squamules, to fugacious appendiculate and to very thick ring like structure encircling the stipe. In some condition of (T. aurantiacus and T. badius) preliminary stage it appears but at matures it become completely disappears, so that practically these characters are very difficult to use identification, because due to its wide range of variation and unstable taxonomic information. In the present study, out of five, two species ( $T$. le-testui and $T$. Schimperi), of Nepalese Termitomyces possess, presence of annulus, of which, one (T. le-testui) was persistent annulus and left of the two species had absence of annulus.

Similarly, the presence of pseudorrhizea of termitomycetes also constitutes a 
distinguishing feature. The length of the hidden pseudorrhizea (if present) varies from 3-60 cm and varies in shape (cylindrical, unevenly widening and narrowing in certain sections). The size of the pseudorrhizea varies between the species, ranging from $\leq 5$ to $\geq 12 \mathrm{~cm}$. Similarly, its length depends on the depth of the termite comb. So, ranging the length we can categorize whether they are belongs. Similarly its shape (morphometry) also varies between the species. They are either solid (or stuffed) or hollow. Presence or absence, solid or hollow, and wideness also help to grading of the species. Surface also varies between the species. Whether they are cartilaginous or leathery or glabroussmooth or fibrillose-stuffed, these characters also helps for narrowing the species among the genus of termitophilous mushrooms. The colour of the pseudorrhizea contrasts sharply with the stipe (white to light brown vs. buffy brown to dark brown). They are either solid (or stuffed) or hollow. Its colour also varies between brown to darkbrown, to pale-grey in colour among the species. According to Vander and Eicker (1990), the aspect of colour and morphometry are not much used as distinguishing characters between species. But, during present investigation its colour and morphometry help for distinguishing between the species. In some respect some species are close resembles to one another, while in some respect they are far apart, eg. T. le-testui and T. schimperi its colour and shape of pseudorrhizea, are dark brown, hollow (T. le-testui), solid (T. schimperi), cylindrical, widening at certain depth, then narrowing down to the point of attachment to the termite nest, (depends on the depth of combs). Whereas other studied species they are contrasting to one another. Presence of an annulus in termitomycetes also serves as an important character, which ranges from none through squamulose and appendiculate to a thick ring encircling the stipe. In the present study, out of five, two species (T. letestui and T. Schimperi), of Nepalese Termitomyces possess, presence of annulus, of which, one have thick and white, ( $T$. letestui) was persistent annulus and left of the three species had absence of annulus.

Presence or absence of clamp connection also helps for narrowing the species. For example T. microcarpus $f$. santalensis have presence of clamp connection rest all studied species have absent. During present investigation it is difficult by only study the hyphal structure for narrowing the taxon, because generally all the species have nonamyloid, hyaline, interwoven, thin walled, though $T$. schimperi is close to one another on the basis of septed, parallel and filamentous hyphae.

According to Heim (1977) and Singer (1986), all the species have pinkish spore in mass and colour of the spore print occasionally turn pale brown with long storage. During present investigation, all the species had pink to brown to pinkish in colour hence justify the statement on this experiment.

Similarly micro-morphological characters also provide crucial information for species descriptions (Harkonen et al., 1995; Bother and Eicker, 1991). Basidia size varies among the species $(15-20 \times 5-7 \mu \mathrm{m}$ of $T$. microcarpus $f$. santalensis) to 26.5$28.5 \times 7-9 \mu \mathrm{m}$ of $T$. schimperi). All of them contain tetra sterigmata but T. umkowaan had larger basidia and basidiospores with comparisons to other. Vander and Eicker (1990) also reported the same. Cystidia size also varies among the species $(19.0 \times 10.5$ of $T$. badius). Its shape was found to be 
useful to more similar species, it stand as a difference between the two species broadly clavate to pyriform (Vander and Eicker, 1990) and obovoid to pyriform (Pegler and Vanhaecke, 1994).

They have little variation of morphometry in basidiospores, thus they provides little taxonomic information for designating the species. All are ellipsoid except T. le-testui, which has oblong in shape. Size of the basidia and basidiospores are diverged. The divergence of one species from other members of the genus suggests that it may be of a different genus (Singer, 1986; Bougher and Katrina, 1998).

Vander and Eicker (1990) distinguished one species to the other using the basidiospores size and shape. This study found inconsistencies in the basidiospores size such that they overlap between the two species, e.g., basidiospores of $T$. aurantiacus. T. badius, T. le $\square$ testui, T. microcarpus $f$. santalensis and T. schimperi has $6.5 \times 4.5 ; 6.5 \times 3.5 ; 7.25 \times 3.5 ; 6.0 \times 4.0$; and $6.5 \times 4.5, \quad$ respectively. This inconsistency and overlap of the basidiospores size limits its use in demarcating the two species.

Micro morphological characters are generally overlapping to one another. For example, basidiospores (elliptical in all four species) but oblong in (T. le-testui) are the little bit contrasting characters to one another. Harkonen et al. (1995), and Bother and Eicker (1991) reported that micromorphological characters of Termitomyces provide little information for species determination. But present study, ample help for narrowing the species. Generally all the species having basidia of tetra sterigmata bearing tetra basidiospores, such results also reported by Heim $(1942,1977)$;
Bels and Pataragetvit, (1982); singer, (1986) and Tibuhwa et al. (2010).

\section{Conclusion}

Although for determining the species, macro and micro-morphological characters provides ample information. But it is not sufficient at all, so that it is necessary to ascertaining the molecular level of study for determining the more similar species in the systematics. During investigation five taxa were identified of the genus Termitomyces. The identify samples are belongs to class: Basidiomycotina; order: Agaricales; family: Tricholomataceae. On the basis of literature Survey, it shows that these all are new addition to the macrofungal flora of Nepal. This research work provides enough information about the genus Termitomyces for the delimitation on taxonomic field. Hence the recent investigation creates an enthusiasm towards intensive exploration on the works.

\section{Acknowledgements}

The authors would like to acknowledge Nepal Academy of Science and Technology for providing research grant. Thanks are due to Central Department of Botany, Tribhuvan University for providing the laboratory facilities. The authors are also grateful to the Institute of Science and Technology for granting study leave to one of them (Mr. Hari Prasad Aryal). Sincere thanks are extended to local people for providing information.

\section{References}

Alexopoulos, C.J. and C.W. Mims 1993. Int. Mycol. $3^{\text {rd }}$ edn, WEL, New Delhi, India. 632p.

Aryal, H.P. and U. Budhathoki 2014. Ethnomycology of Termitomyces spp. R. Heim for its medicinal importance in Nepal. An International Journal of Medicinal Plants New Delhi, India 6(2): 128-137. 
Hari Prasad Aryal and Usha Budathoki / Our Nature (2015), 13(1): 31-44.

Atri, N.S., A. Kaur and H. Kour 2005a. Wild mushrooms - Collection and identification. In: Frontiers in Mushroom Biotechnology (Eds. R.D. Rai, R.C. Upadhyay and S.R. Sharma). NRCM Chambaghat, Solan. pp. 9-26.

Atri, N.S., A. Kaur and H. Kour 2005b. Systematics and sociobiology of Termitophilous mushrooms from Punjab. In: The Fungi-Diversity and Conservation in India (Eds. J.S. Dargan, N.S. Atri and G.S. Dhingra). Bishen Singh Mahendra Pal Singh. pp. 159-182.

Atri, N.S., S.S. Saini, A.K. Gupta, A. Kaur, H. Kour and S.S. Saini 2010. Documentation of wild edible mushrooms and their seasonal availability in Punjab. In: Taxonomy and ecology of Indian fungi (Eds. K.G. Mukerji and C. Manoharachary). I.K. International Publishing House Pvt. Ltd., New Delhi. pp. 161-169.

Bels, P.J. and S. Pataragetvit 1982. Edible mushrooms in Thailand cultivated by Termites. Chinese University Press.

Bother, W.J. and A. Eicker 1991. Cultural studies on the genus Termitomyces in South Africa. 1. Macro and microscopic characters of Basidiome contexst cultures. Mycol. Res. 95: 435-443. http://dx.doi.org/10.1016/S0953-7562(09)80843-5

Bougher, N.L. and S. Katrina 1998. Fungi of Southern Australia. University of Western Australia Press.

Elliott, J.M. 1971. Some methods for the statistical analysis of samples of benthic invertebrates. Sci. Publ. 25. Freshwater Biol. Ass., Ambleside, Westmorland, UK.

Frendenberger, K.S. 2011. A manual for CRS field workers and partner. Freudenberger $228 \mathrm{~W}$. Lexington Street, Baltimore, Maryland 212013443 www.crs.org.

Harkonen, M., T. Niemela and L. Mwasumbi 2003. Tanzanian mushrooms. Edible, harmful and other fungi. Botanical Museum Finnish Museum of Natural History. 200p.

Harkonen, M., T. Saarimaki and L. Mwasumbi 1995. Edible mushroom of Tanzania. Karstenia 35: Suppl., 92p.
Heim, R. 1942. Nouvelles etudes descriptive sur les Agarics termitophiles d'Afrique tropicale. Archives du Muse'um National d'Histoire Naturelle 6(18): 107-166.

Heim, R. 1977. Termites et Champignons. Les termitophiles d'Afrique Noire at d'asie Meridionale. Paris, France: Societe Novelle des Edition. Boubee, Paris. 205p.

Kirk, P., P.F. Cannon, D.W. Minter and J.A. Stalpers 2008. Ainsworth and Bisby's Dictionary of the fungi $10^{\text {th }}$ edn. CAB International, Wallingford, U.K.

Kunugawa, K. and H. Furukawa 1965. The fruit body formation in collybia velutipes induced by lower temperature treatment of one short duration. Bot Mag. 78: 256-273.

Kuo, M. 2006. Making spore prints. Retrieved from the mushroom expert. Com Web site: http://www.mushroomexpert.com/spore_print.htm 1.

Melzer, M.V. 1924. L'ornementation des spores de Russeles. Bul. Soc. Myc. Fr. 40: 78-81. (Not original seen).

Pegler, D.N. and M. Vanhaecke 1994. Termitomyces of Southeast Asia. Kew Bull. 49: 717-736. http://dx.doi.org/10.2307/4118066

Piearce, G.D. 1987. The genus Termitomyces in Zambia. The mycologist. 1: 111-116. http://dx.doi.org/10.1016/S0269-915X(87)800800

Singer, R. 1986. The Agaricales in modern taxonomy, $4^{\text {th }}$ edition, Bishen Singh and Mahendra Pal Singh, Dehradun, India. 981p.

Tibuhwa, D.D., A.K. Kivaisi and F.S.S. Magingo 2010. Utility of the Macro-micro-morphological characterictics used in classifying the species of Termitomyces. Tanz. Jour. Sci. 36: 31-45.

Vander, W.G.C.A. and A. Eicker 1990. Species of Termitomyces in South Africa. Mycologist 94 : 923-937.

Webester, J. 1970. Introduction to Fungi. $2^{\text {nd }}$ Edn., Cambridge University Press, Cambridge. New York. 424p. 